\title{
Multilayer composition coatings for cutting tools: formation and performance properties
}

\author{
Vladimir P. Tabakov ${ }^{1}$, Anatoly S. Vereschaka ${ }^{2}$, and Alexey A. Vereschaka ${ }^{2, *}$ \\ ${ }^{1}$ Ulyanovsk State Technical University, Severnyi Venec32,Ulyanovsk 432027, Russia \\ ${ }^{2}$ Moscow State Technological University STANKIN, Vadkovsky per. 1, Moscow 127994, Russia
}

Received: 1 September 2017 / Accepted: 18 December 2017

\begin{abstract}
The paper considers the concept of a multi-layer architecture of the coating in which each layer has a predetermined functionality. Latest generation of coatings with multi-layered architecture for cutting tools secure a dual nature of the coating, in which coatings should not only improve the mechanical and physical characteristics of the cutting tool material, but also reduce the thermo-mechanical effect on the cutting tool determining wear intensity. Here are presented the results of the development of combined methods of forming multi-layer coatings with improved properties. Combined method of forming coatings using a pulsed laser allowed reducing excessively high levels of compressive residual stress and increasing micro hardness of the multilayered coatings. The results in testing coated HSS tools showed that the use of additional pulse of laser processing increases tool life up to 3 times. Using filtered cathodic vacuum arc deposition for the generation of multilayer coatings based on TiAlN compound has increased the wear-resistance of carbide tools by 2 fold compared with tool life of cutting tool with commercial TiN coatings. The aim of this study was to develop an innovative methodological approach to the deposition of multilayer coatings for cutting tools with functional architectural selection, properties and parameters of the coating based on sound knowledge of coating failure in machining process.
\end{abstract}

Keywords: Multilayer nanostructured coatings / multi-layer architecture / filtered cathodic vacuum arc deposition / wear resistance / PVD coatings

\section{Introduction}

Cutting tools with functional coatings are increasingly used in industry, since they solve a range of complex tasks to improve the productivity of production processes of machining; however, they remain the weak component in the technological process of cutting and limits its development [1-6]. In this context, the challenge to improve compositions and structures of wear-resistant coatings for cutting tools, methods and technologies of their production is relevant and aimed at further improvement of the efficiency of machining. The above is a driving force for further research to improve functional coatings for cutting tools.

Given the dual nature of coatings for cutting tools that, on the one hand, enhance the properties of the tool material, and on the other hand, reduce thermomechanical impact on a tool during the cutting process, this study investigates into multilayer coatings and, in particular, coatings with threelayer architecture that mostly meet the functional require-

\footnotetext{
* e-mail: ecotech@rambler.ru
}

ments for coatings for cutting tools. Such coatings include wear-resistant outer layer, transition intermediate layer, and inner adhesive layer, and each of them has a strictly functional purpose $[2,7-10]$. Lower layer, which is directly adjacent to the substrate, provides a maximum adhesion strength between the coating and the substrate $[9,10]$. Intermediate layer has a multifunctional purpose, and by restraining the intensity of crack formation, it serves as a barrier to diffusion processes between the tool and machined materials and heat flows from areas of friction. Upper wearresistant layer has a minimum compatibility of crystalchemical and mechanical structure with the material being machined; it reduces the power of the friction heat sources and tool wear rate. The performance properties of multilayer composite coatings can be improved through the directed selection of mechanical and crystal-chemical characteristics of its individual layers and its architecture.

Thus, the research objective is to develop methodological guidelines for the formation of multilayer coatings based on the directed selection of architecture, elemental composition and functional properties of the coating layers in view of the laws of failure of coatings during the cutting process. 


\section{Problem statement}

Specific features of the formation of multilayer composite coatings were based on the research into the causes of coating failure at the contact areas of the cutting tool depending on the machining conditions [11-15].

During continuous longitudinal turning, failure of coating occurs because of the formation of cracks on the rake face [16] caused by equivalent stresses. The degree of these stresses is determined by contact loads, temperature in the contact area, and residual stresses in the coating structure [17-20]. The action of equivalent stresses at the elastic contact areas accompanied with the setting process leads to the cyclic nature of the thermal and mechanical stresses that affect the contact surfaces of the cutting tool resulting in fatigue crack propagation, and elastic-plastic deformation of the tool cutting wedge causes the formation of transverse cracks [21]. The highest equivalent stresses occur when carbonitride coatings are used rather than nitride coatings (e.g., TiCN and TiN, TiZrCN and TiZrN), which are characterized by smaller values of fracture toughness and higher coefficient of friction. The above is the main reason for the emergence of the higher contact stresses and temperatures on the rake face of the cutting tool with carbonitride coatings as compared with nitridebased coatings [1].

During intermittent cutting (face milling), the formation of cracks in the coating occurs as a result of the cyclical nature of the changes in thermomechanical stresses in interchange of cutting and idle strokes of the cutting tool [22-31]. Thus, when the amplitude of fluctuation of cyclic loads during the working cycle of the tool increases, then the stresses acting on the rake face and in the cutting tool wedge grow, and the formation of cracks in the coating intensifies. The highest decrease of temperatures and the lowest amplitude of their fluctuations during cutting and idle strokes of the tool are provided by mono-component nitride coatings in comparison with multi-component nitride coatings (e.g., $T i N$ and $\operatorname{TiZrN}$ or $\operatorname{TiZrCrN}$ ), as well as mono-component and multi-component nitride coatings as compared with the corresponding types of carbonitride-based coatings (e.g., TiN and TiCN; TiZrN and $\operatorname{TiZrCN}, \operatorname{TiZrCrN}$ and $\operatorname{TiZrCrCN}$ ).

During the cutting process, normal compressive stresses are formed in coatings, and they inhibit the formation and development of cracks. The level of these stresses increases with the increase of own residual compressive stresses in the coating and its mechanical properties. The greatest normal compressive stresses in the coating structure during the cutting process (for intermittent cutting and during idle stroke of the tool) are provided by multi-element nitride coatings as compared with mono-element coatings (e.g., $\operatorname{TiZrN}$, $\operatorname{TiZrCrN}$, TiAlSiN, and TiN), as well as mono-element and multi-element carbonitride-based coatings as compared with the same type of nitride-based coatings (e.g., TiCN and TiN; TiZrCN and TiZrN, $\operatorname{TiZrCrCN}$ and $\operatorname{TiZrCrN}$ ).

To increase fracture toughness of coatings for the tools operated in various cutting conditions, the following conditions should be maintained.
During continuous cutting, the coating should provide favourable conditions of contact interaction between the machined and tool materials on rake face and reduction of equivalent stresses in the tool cutting wedge and, therefore, increase its stability of shape.

During intermittent cutting, the coating should ensure the greatest possible reduction of temperatures and stresses on the cutting areas of the cutting tool and in the tool cutting wedge, as well as the lowest amplitude of fluctuation during the cutting and idle strokes. When maintained both in longitudinal turning and face milling, these conditions lead to an increase in operation time of the cutting tool till the cracks formation in the coating and its total failure.

To inhibit the processes of crack formation and reduce their intensity both in longitudinal turning and face milling, the mechanical properties and structure of the coating should have residual compressive stresses to enhance the resistance of the coating on the contact surfaces of the tool and ensure maximum time period of favorable impact of the coating on functional cutting parameters (force, temperature, stresses).

Thus, the implementation of these requirements can be realized only in the formation of multilayer architecture of the coating, where each layer performs its specific functions.

In the multilayer coating, the outer layer plays an important role to define the conditions of contact interaction and hence affects the processes causing the formation of cracks in the coating. The outer layer should be selected considering the circs of thermo-mechanical loading of contact surfaces of the cutting tool and the causes of coating failure. Both in continuous and intermittent cutting processes, the underlying layers of the multilayer coating should enhance the opposition of the coating to the processes of cracking, and the adhesion layer in direct contact with the cutting tool surface should provide the high adhesive strength of the coating to the tool substrate.

In view of the above, if to consider the formation of the coating with bilayer architecture with TiN and TiCN layers, it should be noted that the arrangement of layers in such a coating designed for turning and milling will vary. In particular, for the bilayer coating designed for the tool operated in continuous cutting conditions, it is reasonable to use $T i C N$-based layer as the upper layer, and for the tool operated in intermittent cutting conditions TiN-based layer.

The validity of this concept is confirmed by the data in Table 1.

The data presented in Table 1 show that in turning of workpieces of 41CrMo4-DIN steel with carbide inserts with bilayer coating $T i N-T i C N$, time $T_{2}$ till the formation of transverse cracks in the coating is more, and the wear rate $J$ is lower as compared with inserts of WC-Co carbide with $T i C N-T i N$ coating. Milling of workpieces of AISI L6 (HB 240) steel for WC-Co carbide inserts with bilayer $\mathrm{TiCN}$ TiN coating is characterized by a more cycles of the tool work till the formation of longitudinal fractures $N_{1 C}$ in the cutting tool wedge, their entering of the cutting edge $N_{2 C}$ and till the failure of the coating $N_{5 C}$ as compared with the cutting tool with $T i N-T i C N$ coating. 
Table 1. Influence of architecture of multilayer coating on formation of cracks.

\begin{tabular}{|c|c|c|c|c|c|}
\hline \multirow[t]{2}{*}{ Coating } & \multicolumn{3}{|c|}{$\begin{array}{l}\text { End milling }(V=247 \mathrm{~m} / \mathrm{min}, \\
\underline{\left.f_{Z}=0.4 \mathrm{~mm} / \text { tooth }, a_{p}=1.5 \mathrm{~mm}, \mathrm{~B}=20 \mathrm{~mm}\right)}\end{array}$} & \multicolumn{2}{|c|}{$\begin{array}{l}\text { Turning } \\
\left(V=160 \mathrm{~m} / \mathrm{min}, f=0.3 \mathrm{~mm} / \mathrm{rev}, a_{p}=0.75 \mathrm{~mm}\right)\end{array}$} \\
\hline & $N_{1 C}$ & $N_{2 C}$ & $N_{5 C}$ & $\begin{array}{l}\text { Crack formation } \\
\text { Time } T_{2} \text { min }\end{array}$ & Wear rate $\mathrm{J} 10^{-6}, \mathrm{~mm} / \mathrm{m}$ \\
\hline$T i C N-T i N$ & 1820 & 2340 & 14500 & 10.0 & 0.91 \\
\hline$T i N-T i C N$ & 1670 & 1630 & 11800 & 12.5 & 0.52 \\
\hline$T i N-T i Z r N$ & - & - & - & 22.8 & 0.26 \\
\hline TiN-TiAlN & - & - & - & 20.6 & 0.36 \\
\hline$T i N-T i C N-T i Z r N$ & - & - & - & 24.3 & 0.22 \\
\hline
\end{tabular}

Table 2. The main measured parameters of the coating and the measurement methods.

\begin{tabular}{ll}
\hline Measured parameter & Method of measurement \\
\hline Coating thickness & Calotest by fischer sindelfingen \\
Adhesive strength coating and substrate & Scratchtest by csem revetest \\
Nano-hardness modulus $\mathrm{E}_{1}$ & Nano test by nicromaterials ltd.; 25 measurements \\
& on area of $100 \mu \mathrm{m} \times 100 \mu \mathrm{m}$ \\
Phase compositions & X-ray diffractometer of PANalytical empyrean series $2[31]$ \\
\hline
\end{tabular}

As it has been noted above, the operational properties of multilayer coatings can be improved by rational choice of mechanical properties of individual layers and its architecture. Meanwhile, it is very important that the selected elemental composition and the mechanical indicators of each layer correspond to the above approach to the selection of architecture of the multilayer coating.

\section{Methods and materials}

\subsection{Methods for measuring and monitoring the main parameters of the coating}

For the generation of coatings, a vacuum arc device VIT-2 [7-10]. This unit has a number of improvements in comparison with standard arc-PVD units (separation of the microdroplet phase, micro-arc dampening, modernized table rotation system, dynamic gas supply system, etc.). The main measured parameters of the coating and the measurement methods are given in Table 2 .

\subsection{Formation of coating properties by rational selection of their composition}

Hardening of the coating material using a solid solution of additional (alloying) elements is a very effective way to control the formation of the coating properties to improve the efficiency of the tool. The chemical composition of coatings is determined by the layout of the VIT-2 vacuumarc unit. Accordingly, the coating composition depends on the number of cathodes, their position relative to each other, and the distance from the cathodes to the cutting tool during deposition of the coating. When separate cathodes are used, planetary motion of the cutting tool in the unit chamber leads to the formation of super multilayer structure through one turn of table with alternating sublayers of separate phases of coating (e.g., TiN and $Z r N$ ) separated from each other by the transition sublayers of the alternating composition of $T i_{x} Z r_{1-x} N$.

Directional change of the characteristics of the structure, as well as physical and mechanical properties of such coating can be realized by changing the layout of the VIT-2 unit through different combination of sublayers of TiN, $Z r N$ and $T i_{x} Z r_{1-x} N$ and their characteristics (microhardness, thickness, adhesion, etc.). Multicomponent coatings of the same elemental composition (for example, Ti-ZrN), manufactured under different layouts of the unit are characterized by various compositions, parameters and physical and mechanical properties (Fig. 1a), and accordingly, they provide different parameters of efficiency of the cutting tool.

The Physical and mechanical properties of multielement composite coatings depend on the elemental composition of the cathodes used in production. In case of the application of two-element coating, for example, $\operatorname{TiZrN}$, composite cathodes with an embedded zirconium insert into the body of the cathode made of titanium alloy were used. In this case, the coating being formed is a monophase coating when structure has no layers. Such coatings are characterized by lower microhardness and adhesive strength to the carbide substrate as compared with the analogue parameters for $\operatorname{TiZrN}$ coatings obtained from mono-element cathodes. Accordingly, the efficiency of the coated cutting tool is lower. The difference of the mechanical properties of the coatings obtained with the use of separate and composite cathodes can be explained by different mechanisms of hardening of the coating material in condensation thereof [1]. 


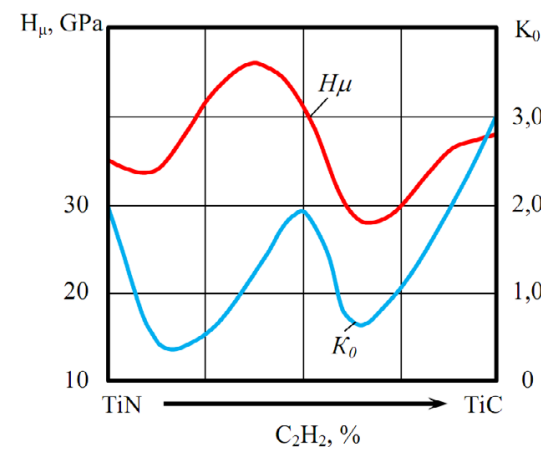

a

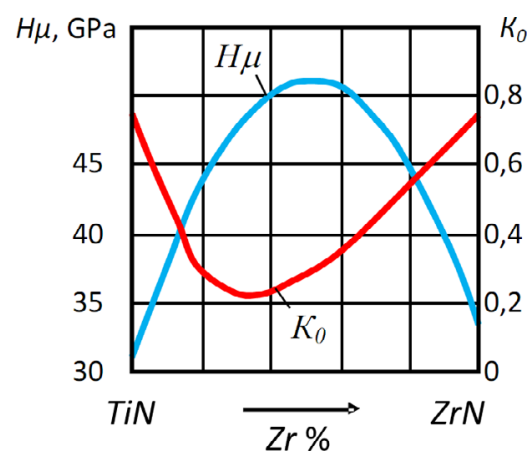

$\mathrm{b}$

Fig. 1. The effect of the content of $\mathrm{Zr}$ and acetylene $\left(\mathrm{C}_{2} \mathrm{H}_{2}\right)$ on the mechanical properties of $\operatorname{TiZrN}(\mathrm{a})$ and $\operatorname{TiZrCN}(\mathrm{b})$.

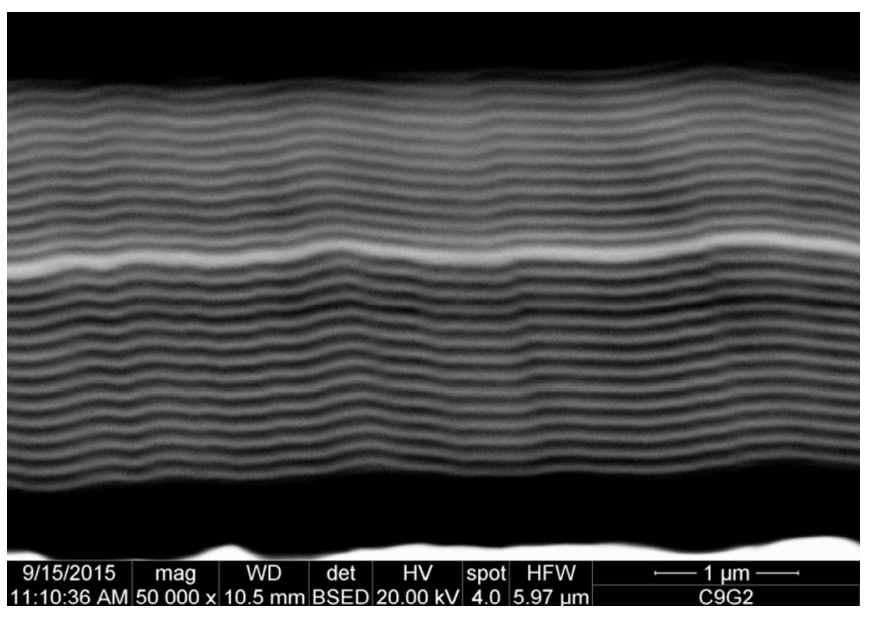

Fig. 2. Microstructure of the coating $T i-T i N-(N b Z r T i A l) N$ in a transverse section.

When designing multilayer-composite coatings used processes enable the development of nano-structured coating materials with balanced hardness, heat resistance and ductility (toughness). Such materials have improved resistance to cracking and premature failure even to thermo-mechanical impact with cyclic character (e.g., interrupted cutting processes).

Significant influence on the properties of the coating has its nanostructure [22-25,32-34].

Figure 2 shows the microstructure of the coating $\mathrm{Ti}$ TiN-(NbZrTiAl)N on transverse sections. With a total coating thickness about $3 \mu \mathrm{m}$ coating has the sub-layer of titanium with thickness of about $0.8 \mu \mathrm{m}$ with no nanosublayers; the TiN layer thickness of about $1.2 \mu \mathrm{m}$, having 26 nano-sublayers with thickness about $46 \mathrm{~nm}$ each, and a wear-resistance layer ( $\mathrm{NbZrTiAl)N}$ thickness of about $1.0 \mu \mathrm{m}$, having a 22 nano-sublayers thickness of about $45 \mathrm{~nm}$ each.

Figure 3 shows the microstructure of the coating $T i$ TiN-(NbZrTi)N on transverse sections. With a total coating thickness about $2.7 \mu \mathrm{m}$ coating has the sub-layer of titanium with thickness of about $0.5 \mu \mathrm{m}$ with no nanolayers; the first $T i N$ layer thickness of about $1.0 \mu \mathrm{m}$, having 11 alternating nano-layers with thickness about 29 and

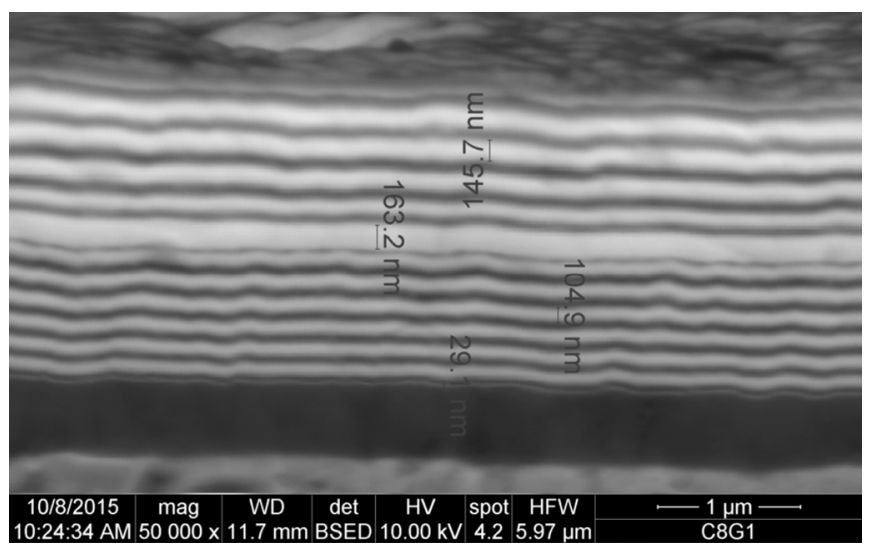

Fig. 3. Microstructure of the coating $T i-T i N-(N b Z r T i) N$ in a transverse section.

$104 \mathrm{~nm}$ each, and a wear-resistance layer (NbZrTi)N thickness of about $1.0 \mu \mathrm{m}$, having a 22 alternating nanosublayers thickness of about 20 and $145 \mathrm{~nm}$ each.

\subsection{Formation of coating properties by changing of composition of a reaction gases}

Basic mechanical and physical properties of modifying coatings for the cutting tool substantially depend on the composition of a reaction gases [35]. In particular, in the deposition of carbonitride coatings, as a working gas medium use a mixture of acetylene and nitrogen. By changing the percentage composition of the gases in the reaction mixture (e.g., by increasing the content of acetylene $C_{2} H_{2}$ ), the desired properties of the coating (Fig. 1b) can be directly created to affect the efficiency of the cutting tool.

\subsection{Formation of coating properties under assisting high energy exposure}

Changes in mechanical properties of the coating can be achieved by exposing the coating to additional modifying treatment to improve the efficiency of the cutting tool. For example, treatment of coating with a pulsed laser radiation 


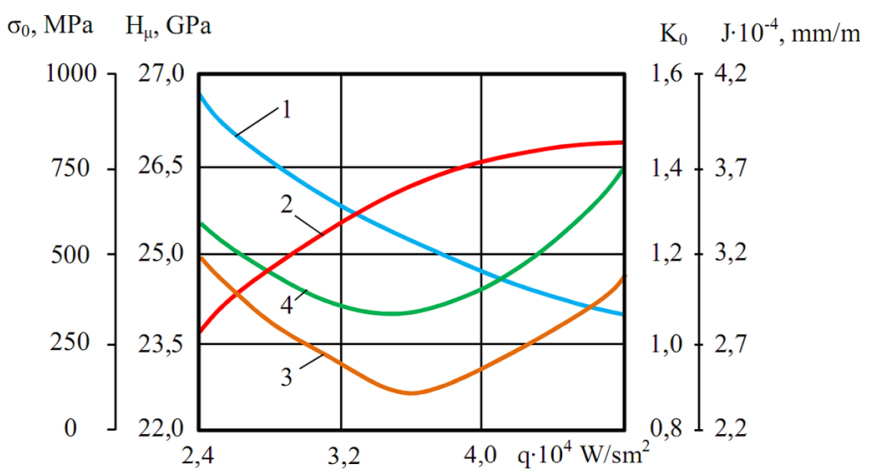

Fig. 4. Influence of the power density of pulsed laser radiation on compressive residual stresses $\sigma_{0}(1)$, microhardness $H \mu(2)$, delamination factor $K_{o}(3)$ of $\operatorname{TiN}$ coating and wear rate $J(4)$ of WC-Co carbide.

leads to reduction of residual stresses, increase of coating microhardness and adhesive strength against the substrate, and that eventually leads to decrease of the wear rate of the cutting tool. This is illustrated in Figure 4 in turning of workpieces of 41CrMo4-DIN steel (HB 230).

\subsection{Formation of coating properties by deposition of adhesive layers}

Formation of high values of residual compressive stresses in the wear-resistant coatings during the process of deposition on the substrate contributes to the growth of their durability due to the increased resistance to the wear during the process of metal machining. On the other hand, the difference of stresses at the "coating-substrate" interface negatively affects the adhesive strength of the coating. Reduction of stress difference and corresponding increase in the strength of adhesion between substrate (tool material) and coating were achieved by the introduction of a transition adhesive layer between them. Application of transition adhesive layers reduces residual stresses and increases the strength of adhesion between substrate and coating, and that fact positively affects the reduction of the wear rate of the cutting tool. The results are shown in Figure 5 in turning of workpieces of $41 \mathrm{CrMo} 4-\mathrm{DIN}$ steel (HB 230).

\subsection{Formation of coating properties by ion assisting during deposition process}

Changes in the physical and mechanical properties of the coating can be achieved by combining the processes of coating deposition and assisting bombardment by highenergy ions of deposited condensate (assisting filtered cathodic vacuum-arc bombardment). The bombardment of the deposited condensate and substrate surface with high-energy ions leads to the modification of the condensate, changes in physical and mechanical and chemical properties of the coating. By varying the energy and density of the flow of bombarding ions, it is possible to adjust grain sizes and orientation and, consequently, to control the mechanical properties, density, stoichiometry and residual stresses in the coating [33,34].

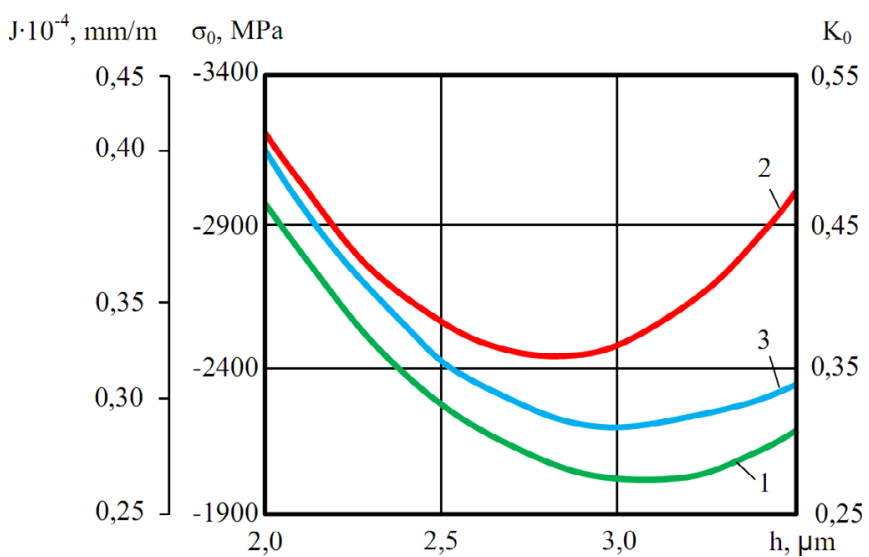

Fig. 5. Influence of the thickness of the transition adhesive layer $h$ on residual compressive stresses $\sigma_{0}(1)$, delamination factor $K_{0}$ (3) of ( Ti-Zr-Fe)-TiZrFeN-TiZrN coating and wear rate $J(3)$ of HSS AISI T11341 inserts ( $6 \% \mathrm{~W}, 5 \% \mathrm{Mo}, 5 \%$ Co, $4 \%$ Cr).

\subsection{Methods of research of tool cutting properties}

During the conducted studies, cutting inserts including $94 \% \mathrm{WC}, 6 \% \mathrm{Co}, 92 \% \mathrm{WC}, 8 \% \mathrm{Co}$ and $78 \% \mathrm{WC}, 14 \% \mathrm{TiC}$, $8 \%$ Co carbides, of square shape, with dimensions of $12.7 \mathrm{~mm} \times 12.7 \mathrm{~mm} \times 4.75 \mathrm{~mm} \quad($ SNUN ISO 031110363 ) were studied. In the process of cutting, the following geometric parameters were used: $\gamma=-8^{\circ} ; \alpha=6^{\circ} ; k=45^{\circ}$; $\lambda=0 ; r=0.8 \mathrm{~mm}$.

The studies were carried out by machining the following materials: Steel C45, steel 41CrMo4-DIN (HB 230), steel AISI 321(HB 180), steel AISI L6 (HB 240).

The properties of the cutting tool were tested using a lathe SLIVEN CU 500 MRD with a thyristor drive (Fig. 6).

\section{Results and discussion}

Improvement of the efficiency of multilayer coating by developing its structure and directed selection of composition and properties each of their layers through the above technological methods of modifying treatment to change the mechanical properties of the coatings will be considered on the example of a two- and three-layer coating with layers of TiN, TiCN, (NbZrTi)N and (NbZrTiAl)N discussed above.

The coating of Ti-TiN-(NbZrTiAl)N showed high content $A l N(48.9 \%)$, TiN (20.4\%) and $\operatorname{ZrN}(8.7 \%)$. The coating Ti-TiN- $(\mathrm{NbZrTiAl}) \mathrm{N}$ showed a high content of $\operatorname{ZrN}(30.8 \%)$ and $\operatorname{TiN}(20.4 \%)$.

In both cases also identified WC (carbide substrate) and a-Ti (a possible trace of microdroplets formed during the deposition of the coating).

To increase the efficiency of TiN-TiCN coating designed for continuous cutting conditions, binary TiAlN and $\operatorname{TiZrN}$ coatings were used as the upper layer, that, in comparison with $T i C N$ coating, are characterized by higher compressive residual stresses and mechanical properties (Tab. 3) and that will increasingly constrain the formation and development of cracks. Besides, TiZrN coating is multilayered, and that fact gives it additional advantages in controlling processes of crack formation. 


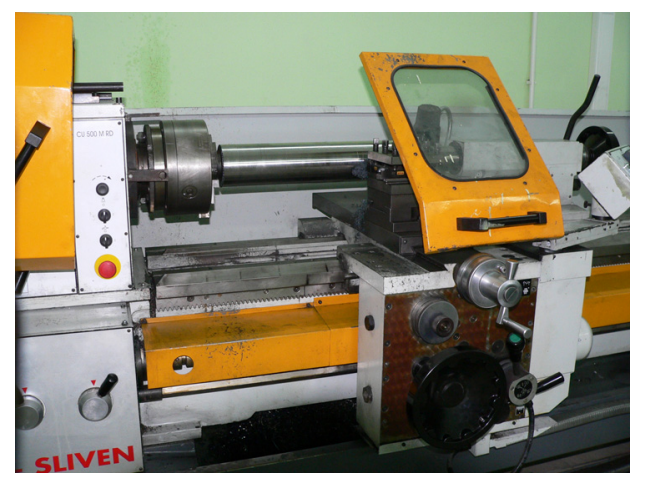

a

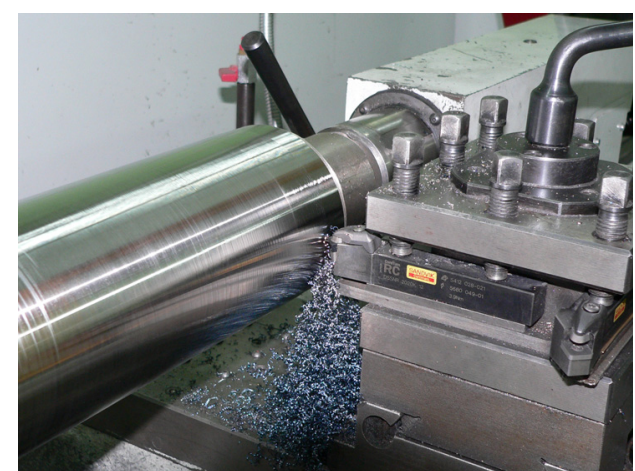

b

Fig. 6. Tool life testing process: general view (a), cutting zone (b).

Table 3. Mechanical properties of wear-resistant coatings.

\begin{tabular}{llllcll}
\hline Coating & $H \mu, \mathrm{GPa}$ & $\sigma_{0}, \mathrm{MPa}$ & $E, \mathrm{GPa}$ & $\sigma_{t}, \mathrm{GPa}$ & $K_{I C}, \mathrm{MPa} \cdot \mathrm{m}^{\frac{1}{2}}$ & $K_{I C P}, \mathrm{MPa} \cdot \mathrm{m}^{\frac{1}{2}}$ \\
\hline TiN & 29.16 & -775 & 307 & 9.53 & 3.39 & 12.29 \\
TiAlN & 38.65 & -1256 & 369 & 12.26 & 4.07 & 14.77 \\
TiZrN & 38.39 & -902 & 379 & 12.38 & 4.22 & 14.44 \\
\hline
\end{tabular}

$H \mu-$ microhardness, $\sigma_{0}-$ residual compressive stresses, $E-$ modulus of elasticity, $\sigma_{t}-$ yield strength, $K_{I C}-$ critical stress intensity factor, $K_{I C P}-$ fracture toughness.

A higher efficiency in controlling processes of crack formation of bilayer $\mathrm{TiN}$ - TiCN coating was obtained due to additional application of outer $\operatorname{TiZrN}$-based layer with multilayer submicrostructure. The use of multilayer coatings of TiN-TiAlN, TiN-TiZrN, TiN-TiCN-TiZrN, Ti$\operatorname{TiN}-(\mathrm{NbZrTi}) N$ and $T i-T i N-(N b Z r T i A l) N$ increases the time period of the tool operation till the formation of transverse cracks in the area of plastic contact of chip and rake face as compared with $\mathrm{TiN}$ - TiCN coating. Meanwhile, the maximum increase in the tool life was provided by three-layer TiN-TiCN-TiZrN and Ti-TiN-(NbZrTiAl)N coating. The conducted wear tests (Fig. 7) have confirmed the high efficiency of the proposed coatings had increased the wear resistance of carbide inserts in machining of AISI L6 (HB 240) steel by factor of 1.4-3.3 in comparison with wear resistance of inserts with $\mathrm{TiN}-\mathrm{TiCN}$ coatings.

The operational properties of a bilayer TiCN-TiN coating designed for milling can be improved through application of an intermediate $\operatorname{TiZrN}$ multilayer ( $T i C N$ TiZrN-TiN coating), providing increase of its fracture toughness. As it can be seen from Figure 7, TiCN-TiZrNTiN coating is characterized by a lower number of cracks and smaller area of its fracture as compared with $\mathrm{TiCN}$ TiN coating during the same period of the tool operation.

Abrasion resistance of the outer wear-resistance layer can be improved by it application at a low temperature $\left(\mathrm{TiN}_{\mathrm{KTR}}\right)$, which will increase its microhardness (Tab. 3). The conducted wear tests have shown that the use of the above methods of technological changes in the mechanical characteristics of the separate layers of coating $\mathrm{TiCN}$ $T i Z r N-T i N$ can improve its efficiency.
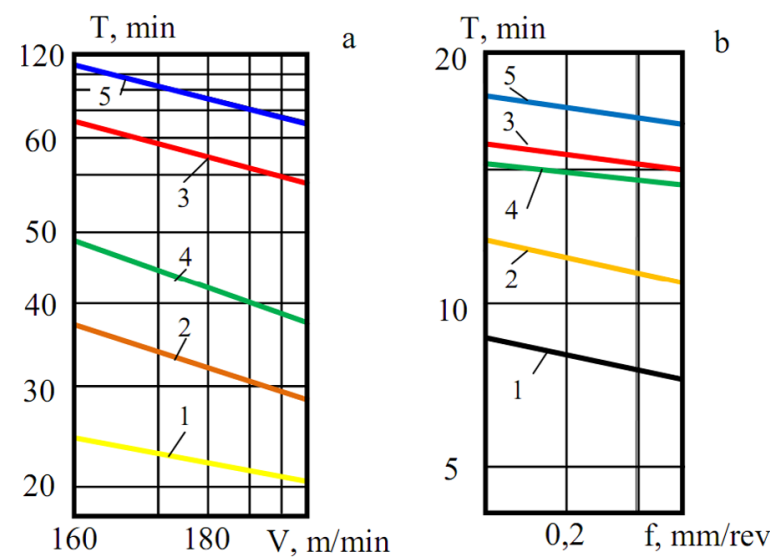

Fig. 7. Influence of the cutting speed $V$ (a), in the period of durability $T$ of coated carbide inserts in turning workpieces of AISI L6 (HB 240): 1-TiN; 2-TiN-TiCN; 3-TiN-TiZrN; 4-TiNTiAlN; 5-TiN-TiCN-TiZrN.

The highest increase in tool life up to 1.7 times as compared with $\mathrm{TiCN}$ - TiN coating was provided by $\mathrm{TiCN}$ TiZrN-TiN coating. As compared with the use of monolayer TiN coating, the application of three-layer coatings increases the tool life up to 3.5 times, and as compared with uncoated tool up to 7.2 times, depending on the composition of multilayer coating and the mode of machining.

Increase in the operational properties of the cutting tool through the selection of the rational composition and thickness of transition adhesive layers in multilayer coating 

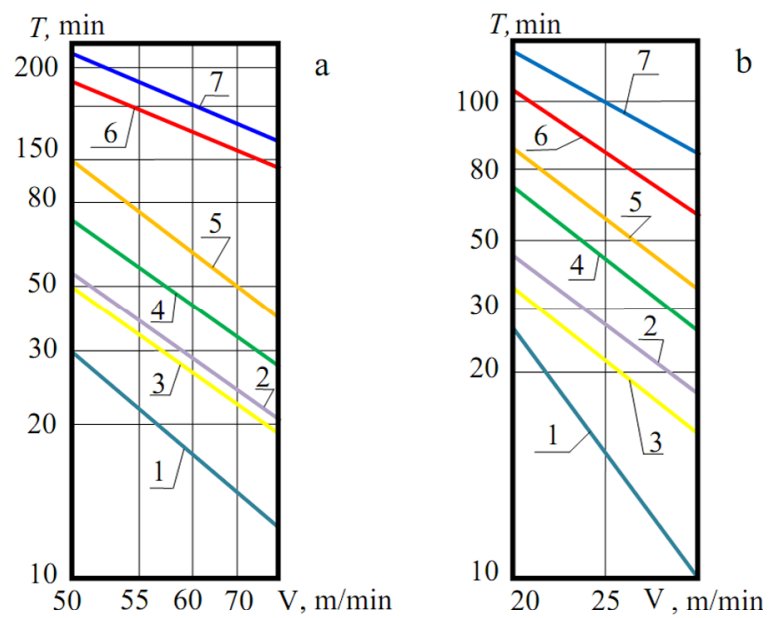

Fig. 8. Influence of cutting speed $V$ on the tool life $T$ of coated inserts in turning workpieces of $41 \mathrm{CrMo} 4-\mathrm{DIN}$ (HB 230) $(a)$ and AISI 321(HB 180) steels (b): 1- TiN; 2-TiZrN; 3-TiFeN-TiN; 4(Ti-Fe)-TiFeN-TiN; 5-(Ti-Zi-Fe)-TiZrFeN-TiZrN; 6-(Ti-Fe)TiFeN-TiN + LO, 7-(Ti-Zi-Fe)-TiZrFeN-TiZrN +LO.

is shown in Figure 8. As it can be seen, in machining of workpieces of steel 41CrMo4 - DIN (HB 230) and steel AISI 321(HB 180), the application of multilayer coatings with transition $T i F e N$ layer can increase the tool life by $1.4-1.9$ times as compared with $T i N$ coating depending on the mode of cutting. The increase in adhesive strength with the tool base through introducing additional transition adhesive layer (Ti-Fe) in the architecture of TiFeN-TiN coating increases the tool life by 2.0-3.0 times. Even higher efficiency is typical for high-speed cutting tools with multilayer coatings, including multilayer upper $\operatorname{TiZrN}$ layer. The period of durability of the tool is $2.6-4.2$ times and 1.3-1.9 times higher, respectively, as compared with monolayer TiN and $\operatorname{TiZrN}$ coatings depending on the machining conditions.

Figure 8 shows the increase in the efficiency of the cutting tool through the selection of the composition and thickness of transition adhesive layers in multilayer coating (at $a_{p}=1.5 \mathrm{~mm}, f=0.2 \mathrm{~mm} / \mathrm{rev}$ and feed $f$ (b) at $\left.V=180 \mathrm{~m} / \mathrm{min}, \quad a_{p}=1.5 \mathrm{~mm}\right)$. As it can be seen, in machining of workpieces of 41CrMo4-DIN (HB 230) and AISI 321(HB 180) steels, the application of multilayer coatings with transition $\mathrm{TiFeN}$ layer can increase the tool life by 1.4-1.9 times as compared with TiN coating depending on the mode of cutting. The increase in adhesive strength with the tool base through introducing additional transition adhesive layer (Ti-Fe) in the architecture of TiFeN-TiN coating increases the tool life by 2.0-3.0 times.

An example of implementation of additional treatment of the multilayer coating with pulsed laser radiation to increase its efficiency is shown in Figure 8 (lines 4-7) (Fig. 9a: $f=0.3 \mathrm{~mm} / \mathrm{rev}, a_{p}=0.75 \mathrm{~mm}$; Fig. $9 \mathrm{~b}: f=0.3 \mathrm{~mm}$, $\left.a_{p}=0.5 \mathrm{~mm}\right)$. Pulsed laser treatment reduces the value of residual compressive stresses that contributes to the increase in the adhesive strength of the multilayer coating with tool base and increases the microhardness of the multilayer coating. As a result, the efficiency of high-speed cutting tools increases. As it can be seen from Figure 8,
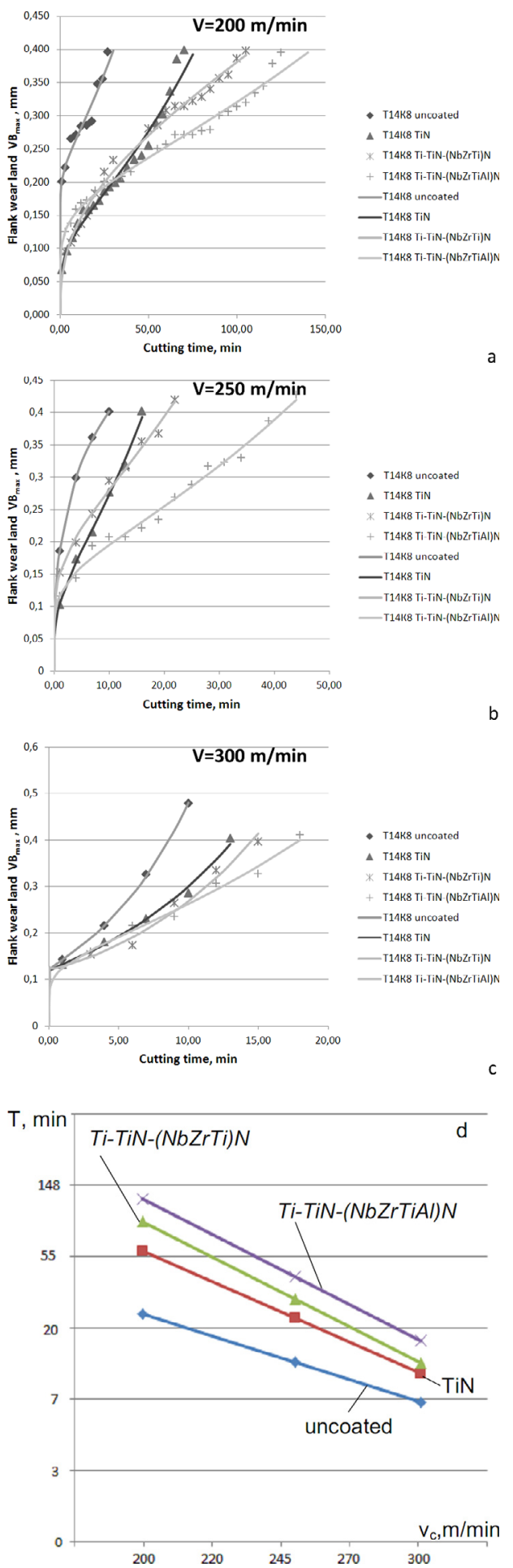

Fig. 9. Dependence flank wear land $\mathrm{VB}_{\max }$ for inserts made of WC-TiC-Co carbide of cutting time for a workpiece of steel C45 and the influence of the cutting speed on tool wear (d).

pulsed laser treatment of multilayer coating increases the tool life up to 3 times, depending on the cutting conditions and class of the material being machined.

The life tests carried out in Figure 9 also showed a high efficiency of the developed three-layer nanostructured

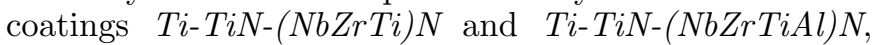


which increased resistance of inserts made of WC-TiC-Co carbide for longitudinal turning steel $\mathrm{C} 45$ in 1.4-2 times in comparison with with uncoated and coated with "commercial" TiN inserts. At that coating Ti-TiN-(NbZrTiAl)N showed significantly higher life time than the coating $T i$ $T i N-(N b Z r T i) N$ at all cutting speeds (with $a_{p}=1.0 \mathrm{~mm}$; $f=0.2 \mathrm{~mm} /$ rev., $\quad V=200 \mathrm{~m} / \mathrm{min} \quad$ (a), $\quad 250 \mathrm{~m} / \mathrm{min} \quad$ (b), $300 \mathrm{~m} / \mathrm{min}(\mathrm{c}))$. Longer life of the coatings can be explained as nanolayers less thickness and therefore more of them, and by availability $A l$ in the surface layer.

\section{Conclusions}

The analysis of the results of the conducted research allows making the following conclusions:

- formation of multilayer coatings should be carried out taking into account the requirements for coating and the machining conditions defining the nature of fracture of coating during the cutting process;

- the maximum efficiency of multilayer coatings is provided by the directional selection of architecture, rational composition, structure, and mechanical properties of the separate layers in view of the proposed methodological approaches to the formation of multilayer coatings for cutting tools;

- selection of the mechanical properties of the layers of the multilayer coating can be achieved through the use of various technological methods of coating formation (change in temperature conditions, composition of coating and composition of reaction gas, structure of evaporating cathodes, combination of processes of condensation of coating and ion bombardment) and additional energy impact on the coating material;

- the use of multilayer coatings of the new generation allows to increase tool life not only in comparison with the uncoated tool (up to $3-4$ times), but also in comparison with the tool with "reference" TiN coating (2 times and more).

Acknowledgements. The authors are very grateful to the late Professor Anatoly Stepanovich Vereschaka of Moscow State Technological University STANKIN for his valuable contributions to this work. He is remembered with affection by the authors and by all those who enjoyed and were touched by his company during his lifetime.

This research was financed by the Ministry of Education and Science of the Russian Federation in the framework of the state order in the sphere of scientific activity (Leading researchers, project $16.9575 .2017 / 6.7)$.

\section{References}

[1] V.P. Tabakov, Formirovaniye iznosostoykikh ionno-plazmennykh pokrytiy rezhushchego instrumenta, Mashinostroyeniye, Moscow, 2008 (in Russian)

[2] A.S. Vereschaka, Working capacity of the cutting tool with wear resistant coatings, Mashinostroenie, Moscow, 1993 (in Russian)
[3] B.D. Beake, G.S. Fox-Rabinovich, Progress in high temperature nanomechanical testing of coatings for optimizing their performance in high speed machining, Surf. Coat. Technol. 255 (2014) 102-111

[4] M.G. Faga, G. Gautier, R. Calzavarini, M. Perucca, E. Aimo Boot, F. Cartasegna, L. Settineri, AlSiTiN nanocomposite coatings developed via Arc Cathodic PVD: evaluation of wear resistance via tribological analysis and high speed machining operations, Wear 263 (2007) 1306-1314

[5] G. Skordaris, K.-D. Bouzakis, T. Kotsanis, P. Charalampous, E. Bouzakis, O. Lemmer, S. Bolz, Film thickness effect on mechanical properties and milling performance of nanostructured multilayer PVD coated tools, Surf. Coat. Technol. 307 (2016) 452-460

[6] M. Tkadletz, N. Schalk, R. Daniel, J. Keckes, C. Czettl, C. Mitterer, Advanced characterization methods for wear resistant hard coatings: a review on recent progress, Surf. Coat. Technol. 285 (2016) 31-46, DOI:10.1016/j.surf coat.2015.11.016

[7] A.A. Vereshchaka, A.S. Vereshchaka, O. Mgaloblishvili, M. N. Morgan, A.D. Batako, Nano-scale multilayered-composite coatings for the cutting tools, Int. J. Adv. Manuf. Technol. 72 (2014) 303-317

[8] A.A. Vereschaka, M.A. Volosova, A.D. Batako, A.S. Vereshchaka, B.Y. Mokritskii, Development of wear-resistant coatings compounds for high-speed steel tool using a combined cathodic vacuum arc deposition, Int. J. Adv. Manuf. Technol. 84 (2016) 1471-1482, DOI:10.1007/s00170015-7808-5

[9] A.O. Volkhonskii, A.A. Vereshchaka, I.V. Blinkov, A.S. Vereshchaka, A.D. Batako, Filtered cathodic vacuum Arc deposition of nano-layered composite coatings for machining hard-to-cut materials, Int. J. Adv. Manuf. Technol. 84 (2016) 1647-1660, DOI:10.1007/s00170-015-7821-8

[10] A.A. Vereschaka, A.S. Vereschaka, A.D. Batako, O. Kh. Hojaev, B.Y. Mokritskii, Development and research of nanostructured multilayer composite coatings for tungsten-free carbides with extended area of technological applications, Int. J. Adv. Manuf. Technol. 87 (2016) 3449-3457, DOI:10.1007/s00170-016-8739-5

[11] G.S. Fox-Rabinovich, A.I. Kovalev, M.H. Aguirre, B.D. Beake, K. Yamamoto, S.C. Veldhuis, J.L. Endrino, D.L. Wainstein, A.Y. Rashkovskiy, Design and performance of AlTiN and TiAlCrN PVD coatings for machining of hard to cut materials, Surf. Coat. Technol 204 (2009) 489-496, DOI:10.1016/j.surfcoat.2009.08.021

[12] Q. Yang, R. McKellar, Nanolayered CrAlTiN and multilayered CrAlTiN-AlTiN coatings for solid particle erosion protection, Tribol. Int. 83 (2015) 12-20, DOI:10.1016/j. triboint.2014.11.002

[13] S. Koseki, K. Inoueb, H. Usuki, Damage of physical vapor deposition coatings of cutting tools during alloy 718 turning, Precis. Eng. 44 (2016) 41-54

[14] L. Lu, Q.M. Wang, B.Z. Chen, Y.C. Ao, D.H. Yu, C.Y. Wang, S.H. Wu, K.H. Kim, Microstructure and cutting performance of CrTiAlN coating for high-speed dry milling, Trans. Nonferrous Met. Soc. China 24 (2014) 1800-1806, DOI:10.1016/S1003-6326(14)63256-8

[15] J.L. Endrino, G.S. Fox-Rabinovich, C. Gey, Hard AlTiN, AlCrN PVD coatings for machining of austenitic stainless steel, Surf. Coat. Technol. 200 (2006) 6840-6845, DOI:10.1016/j.surfcoat.2005.10.030 
[16] A.S. Vereschaka, A.A. Vereschaka, D.V. Sladkov, A.Yu. Aksenenko, N.N. Sitnikov, Control of structure and properties of nanostructured multilayer composite coatings applied to cutting tools as a way to improve efficiency of technological cutting operation, J. Nano Res. 37 (2016) 51-57, DOI:10.4028/www.scientific.net/JNanoR.37.51

[17] L. Chen, Y. Du, P.H. Mayrhofer, S.Q. Wang, J. Li, The influence of age-hardening on turning and milling performance of Ti-Al-N coated inserts, Surf. Coat. Technol. 202 (2008) 5158-5161, DOI:10.1016/j.surfcoat.2008.05.036

[18] K. Yamamoto, T. Sato, K. Takahara, K. Hanaguri, Properties of $(\mathrm{Ti}, \mathrm{Cr}, \mathrm{Al}) \mathrm{N}$ coatings with high $\mathrm{Al}$ content deposited by new plasma enhanced arc-cathode, Surf. Coat. Technol. 174-175 (2003) 620-626, DOI:10.1016/S0257-8972 (03)00580-2

[19] S. Veprek, M.J.G. Veprek-Heijman, Industrial applications of superhard nanocomposite coatings, Surf. Coat. Technol. 202 (2008) 5063-5073, DOI:10.1016/j.surfcoat.2008.05.038

[20] G.S. Fox-Rabinovich, K. Yamamoto, A.I. Kovalev, S.C. Veldhuis, L. Ning, L.S. Shuster, A. Elfizy, Wear behavior of adaptive nano-multilayered $\mathrm{TiAlCrN} / \mathrm{NbN}$ coatings under dry high performance machining conditions, Surf. Coat. Technol. 202 (2008) 2015-2022, DOI:10.1016/j.surf coat.2007.08.067

[21] M.G. Faga, G. Gautier, R. Calzavarini, M. Perucca, E. Aimo Boot, F. Cartasegna, L. Settineri, AlSiTiN nanocomposite coatings developed via Arc Cathodic PVD: evaluation of wear resistance via tribological analysis and high speed machining operations, Wear 263 (2007) 1306-1314

[22] L. Ning, S.C. Veldhuis, K. Yamamoto, Investigation of wear behavior and chip formation for cutting tools with nanomultilayered TiAlCrN/NbN PVD coating, Int. J. Mach. Tools Manuf. 48 (2008) 656-665, DOI:10.1016/j.ijmach tools.2007.10.021

[23] K. Yamamoto, S. Kujime, K. Takahara, Properties of nanomultilayered hard coatings deposited by a new hybrid coating process: combined cathodic arc and unbalanced magnetron sputtering, Surf. Coat. Technol. 200 (2005) 435439, DOI:10.1016/j.surfcoat.2005.02.175

[24] S. Yang, E. Wiemann, D. Teer, The properties and performance of Cr-based multilayer nitride hard coatings using unbalanced magnetron sputtering and elemental metal targets, Surf. Coat. Technol. 188 (2004) 662-668, DOI: 10.1016/j.surfcoat.2007.08.067

[25] H. Ezuraa, K. Ichijoa, H. Hasegawab, K. Yamamotoc, A. Hottaa, T. Suzukia, Micro-hardness, microstructures and thermal stability of ( $\mathrm{Ti}, \mathrm{Cr}, \mathrm{Al}, \mathrm{Si}) \mathrm{N}$ films deposited by cathodic arc method, Vacuum 82 (2008) 476-481

[26] C.-H. Lai, K.-H. Cheng, S.-J. Lin, J.-W. Yeh, Mechanical and tribological properties of multi-element (AlCrTaTiZr) N coatings, Surf. Coat. Technol. 202 (2008) 3732-3738

[27] V.P. Tabakov, The influence of machining condition forming multilayer coatings for cutting tools, Key Eng. Mater. 496 (2012) 80-85

[28] V.P. Tabakov, A.S. Vereschaка, Development of technological means for formation of multilayer composite coatings, providing increased wear resistance of carbide tools, for different machining condition, Key Eng. Mater. 581 (2014) $55-61$

[29] A.S. Vereschaka, S.N. Grigoriev, V.P. Tabakov, E.S. Sotova, A.A. Vereschaka, M.Yu. Kulikov, Improving the efficiency of the cutting tool made of ceramic when machining hardened steel by applying nano-dispersed multi-layered coatings, Key Eng. Mater. 581 (2014) 68-73

[30] F. Klocke, K.-D. Bouzakis, K. Georgiadis, S. Gerardis, G. Skordaris, M. Pappa, Adhesive interlayers' effect on the entire structure strength of glass molding tools' $\mathrm{Pt}$-Ir coatings by nano-tests determined, Surf. Coat. Technol. 206 (2011) 1867-1872

[31] A.A. Vereschaka, S.N. Grigoriev, Study of cracking mechanisms in multi-layered composite nano-structured coatings, Wear $\quad 378-379 \quad$ (2017) 43-57, DOI:10.1016/j. wear.2017.01.101

[32] Z.G. Zhang, O. Rapaud, N. Allain, D. Mercs, M. Baraket, C. Dong, C. Coddet, Microstructures and tribological properties of $\mathrm{CrN} / \mathrm{ZrN}$ nanoscale multilayer coatings, Appl. Surf. Sci. 255 (2009) 4020.

[33] A.A. Vereschaka, M.A. Volosova, A. Batako, A.S. Vereschaka, N.N. Sitnikov, A.E. Seleznev, Nano-scale multilayered coatings for improved efficiency of ceramic cutting tools, Int. J. Adv. Manuf. Technol. (2017) 27-43, DOI:10.1007/s00170-016-9353-2

[34] A.A. Vereschaka, S.N. Grigoriev, N.N. Sitnikov, A. Batako, Delamination and longitudinal cracking in multi-layered composite nano-structured coatings and their influence on cutting tool life, Wear 390-391 (2017) 209-219, DOI:10.1016/j.wear.2017.07.021

[35] A.A. Vereschaka, A.S. Vereschaka, J.I. Bublikov, A.Y. Aksenenko, N.N. Sitnikov, Study of properties of nanostructured multilayer composite coatings of Ti-TiN-(TiCrAl)N and Zr-ZrN-(ZrNbCrAl)N, J. Nano Res. 40 (2016) 90-98, DOI:10.4028/www.scientific.net/JNanoR.40.90

Cite this article as: V.P. Tabakov, A.S. Vereschaka, A.A. Vereschaka, Multilayer composition coatings for cutting tools: formation and performance properties, Mechanics \& Industry 18, 706 (2017) 